\title{
Deprescribing in the Older Patient: A Narrative Review of Challenges and Solutions
}

\author{
Harry Wu' \\ Lisa Kouladjian O’Donnell' \\ Kenji Fujita (D) \\ Nashwa Masnoon ${ }^{1,2}$ \\ Sarah N Hilmer (D) \\ 'Departments of Clinical Pharmacology \\ and Aged Care, Faculty of Medicine and \\ Health, The University of Sydney, Kolling \\ Institute, Royal North Shore Hospital, \\ Sydney, NSW, Australia; ${ }^{2}$ Department of \\ Pharmacy, Royal North Shore Hospital, \\ St Leonards, NSW, Australia
}

\begin{abstract}
Polypharmacy is a major challenge in healthcare for older people, and is associated with increased risks of adverse outcomes, such as delirium, falls, frailty, cognitive impairment and hospitalization. There is significant public and professional interest in the role of deprescribing in reducing medication-related harms in older people. We aim to provide a narrative review of 1) the safety and efficacy of deprescribing interventions, 2) the challenges and solutions of deprescribing research and implementation in clinical practice, and 3) the benefits of using Computerized Clinical Decision Support Systems (CCDSS) and Quality Indicators (QIs) in deprescribing research and practice. Deprescribing is an established management strategy to minimize polypharmacy and potentially inappropriate medications. There is limited clinical evidence for its efficacy on global and geriatric outcomes. Various challenges at patient, healthcare professional and healthcare system levels may impact on the success of deprescribing interventions in research and practice. Management strategies that target all levels of the healthcare system are required to overcome these challenges. Future studies may consider large multicenter prospective designs to establish the effects and sustainability of deprescribing interventions on clinical outcomes.

Keywords: deprescribing, polypharmacy, geriatric, older people, computerized clinical decision support, quality indicator
\end{abstract}

\section{Introduction}

Optimising use of medications is increasingly recognized as an important pillar in the management of older people. Polypharmacy is highly prevalent among older people; it is estimated that more than 15 million Americans aged 65 years and older are prescribed five or more medications. ${ }^{1}$ This number is very likely to rise as the population grows older. Population-based studies have demonstrated that polypharmacy is independently associated with increased risks of adverse geriatric outcomes such as delirium, falls, frailty, cognitive impairment and hospitalization. ${ }^{2-5}$ With increasing burdens of geriatric syndromes and age-related diseases, ${ }^{6-8}$ there is significant public interest in reducing medication-related harms in older people. ${ }^{9}$ Reduction of inappropriate polypharmacy is a major public health goal identified by the World Health Organization Third Global Patient Safety Challenge: Medication Without Harm. ${ }^{10}$ This has led to a greater awareness of optimising medication use and the need to improve management strategies to prevent medication-related problems in older people.

The term "deprescribing" was first published nearly two decades ago, ${ }^{11}$ and is defined as the process of supervised withdrawal of inappropriate medications, for which the potential harms outweigh the benefits. ${ }^{12}$ The main rationale of
Correspondence: Sarah N Hilmer Research, Royal North Shore Hospital Reserve Road, St Leonards, NSW, 2065, Australia

Tel +6I29926448I

Email sarah.hilmer@sydney.edu.au 
deprescribing is to improve patient outcomes and minimize the adverse events associated with inappropriate medications and polypharmacy, through patient involvement, shared-decision making and goal-directed care. ${ }^{13}$ Given the rapidly expanding field of deprescribing research, this narrative review aims to provide an update on the current evidence on deprescribing to inform and guide clinicians in medication review for older people. Specifically, this review aims to 1) provide a summary of the literature on the safety and efficacy of deprescribing interventions; 2) synthesize challenges and their solutions, for deprescribing interventions in research and practice; and 3) summarize current evidence on two prominent emerging solutions in deprescribing research and practice: Computerized Clinical Decision Support Systems (CCDSS) and Quality Indicators (QIs).

\section{Methods}

We performed literature searches in Medline and Embase, focusing on systematic reviews published from January 2016 to March 2021 using the following search terms: "deprescribing", "polypharmacy", "inappropriate medications", "inappropriate prescribing", "challenges", "barriers", "obstacles", "computerized clinical decision support", "quality indicator", "clinical indicator", "performance measure", "aged", "older" and "geriatric". The search strategy was limited to English language where abstracts were available for review. We excluded studies where patient cohorts were not representative of the older population. In addition, editorials, commentaries, conference abstracts, case reports, un-published studies (grey literature), narrative review articles and non-systematic reviews were excluded. The abstract and title of each publication were reviewed to determine their relevance to the research questions. Systematic reviews were included if they fulfilled the following criteria: a study population that included patients with a median age of 60 years and older, and examined the 1) safety and efficacy of deprescribing interventions on potentially inappropriate medications (PIMs) and patient global health outcomes, such as mortality, hospitalization, quality of life and geriatric syndromes (falls, functional and cognitive impairment), 2) challenges of and solutions for deprescribing research and implementation, 3) use of Computerized Clinical Decision Support Systems (CCDSS) and 4) Quality Indicators (QIs) in deprescribing research. After screening the titles and abstracts of records from literature searches, the full texts of articles deemed potentially eligible were reviewed. References of included systematic reviews were also screened for their relevance to ensure that no potentially eligible publications were missed. The following data from relevant publications were extracted: first author, year of publication, study population (age, clinical setting: hospital, community or nursing home), deprescribing target (specific medication class or any medication), number and type of studies included in the systematic review (randomized controlled trial, non-randomized controlled trial), impact on medication use, impact on global health outcomes (mortality, hospitalization, quality of life and geriatric syndromes), and adverse drug withdrawal effects. Specific numerical data in the forms of odds ratio $(\mathrm{OR})$, risk ratio $(\mathrm{RR})$ or mean difference (MD) and 95\% confidence interval were only reported if the study had performed meta-analyses of the outcomes of interest, and we opted for a narrative summary of our findings.

\section{Safety and Efficacy Data on Deprescribing}

Emerging evidence suggests that deprescribing is safe and feasible as a management strategy in patients at risk of medication-related problems. Deprescribing can reduce the number of potentially inappropriate medications. It rarely causes adverse drug withdrawal events and there is limited evidence of its effects on global and geriatric outcomes. Table 1 summarizes systematic reviews examining the safety and efficacy of deprescribing interventions.

To date, most clinical studies have failed to consistently demonstrate an effect of deprescribing interventions on clinical outcomes such as falls, hospitalization, cognitive and physical function decline. ${ }^{14}$ This is partly because most deprescribing studies have relatively small sample sizes and have residual confounding by factors that are not accounted for in the analysis. In addition, it may take many years to reverse some of the geriatric outcomes such as physical and cognitive decline, and the prolonged study duration and intensive multidisciplinary interventions may be cost-prohibitive for most deprescribing trials. In light of these challenges, the data on efficacy of deprescribing interventions is currently limited. The benefits and sustainability of these interventions on long-term quality of life, morbidity and geriatric outcomes remain unclear. Large randomized controlled multicenter trials are needed to define the true efficacy of deprescribing interventions in older population. 


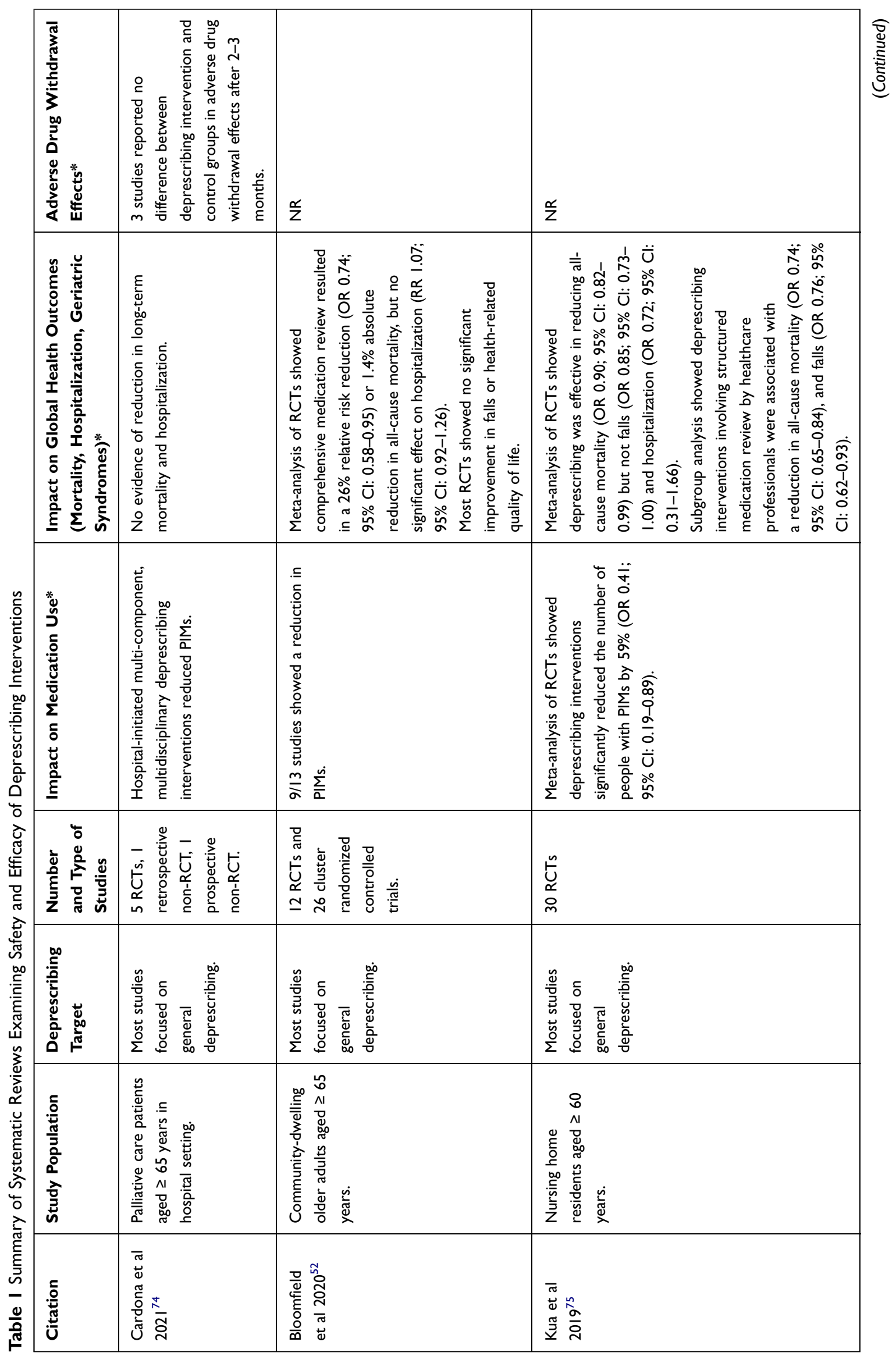




\begin{tabular}{|c|c|c|c|c|c|}
\hline 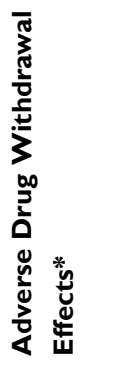 & $\stackrel{\mathscr{K}}{Z}$ & 営 & 号 & $\stackrel{\mathscr{N}}{Z}$ & $\stackrel{\mathscr{c}}{Z}$ \\
\hline 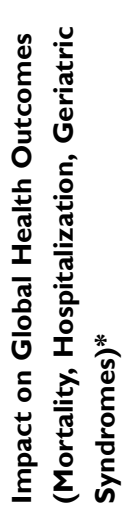 & 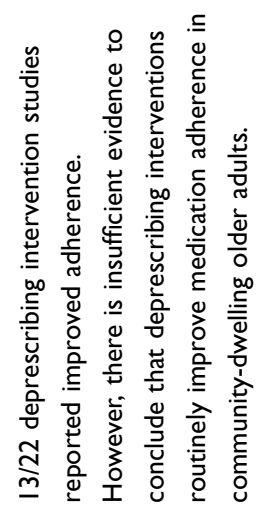 & 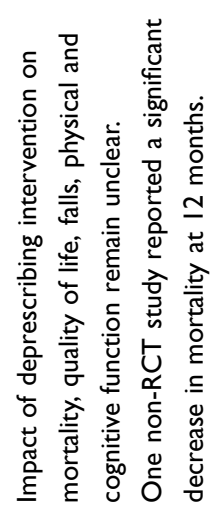 & 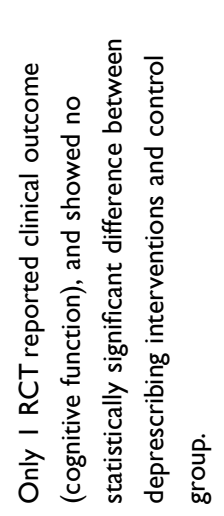 & 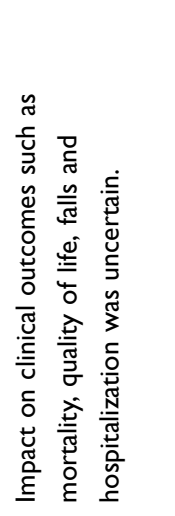 & 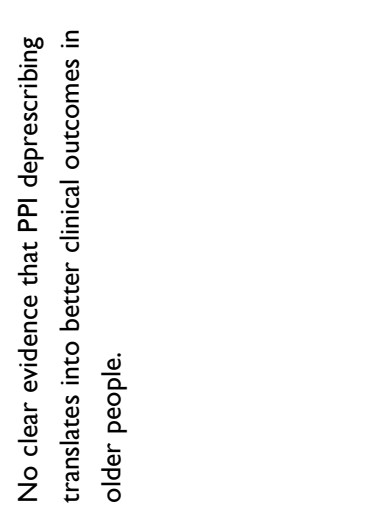 \\
\hline 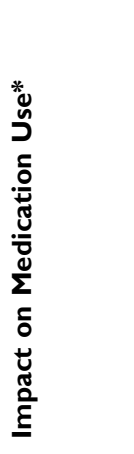 & 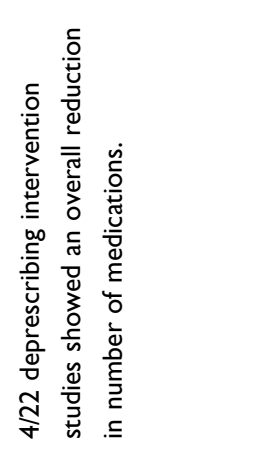 & 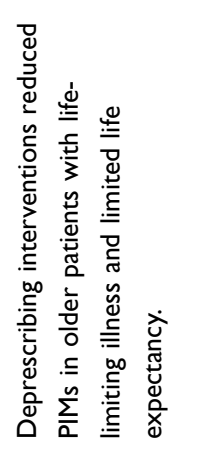 & 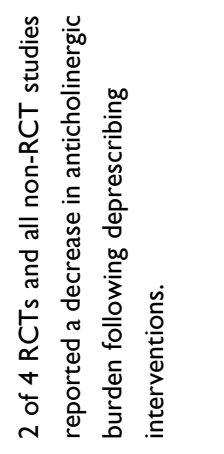 & 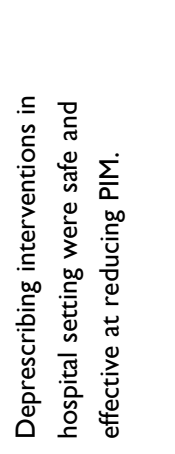 & 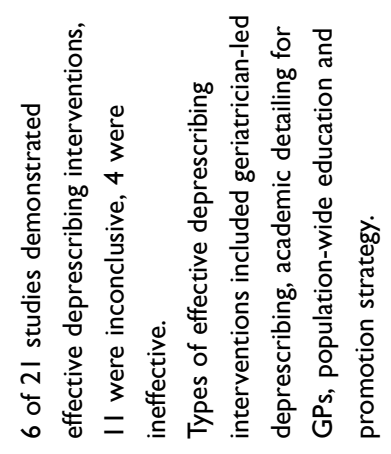 \\
\hline 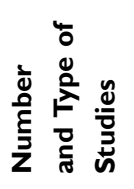 & 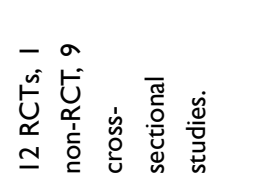 & 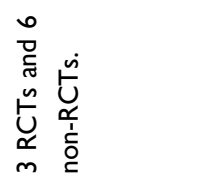 & 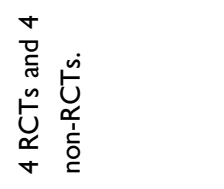 & $\begin{array}{l}\stackrel{\varrho}{U} \\
\alpha \\
a\end{array}$ & 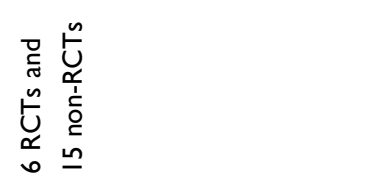 \\
\hline 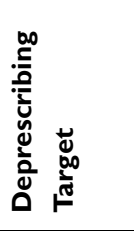 & 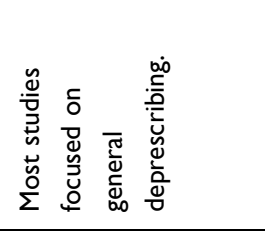 & 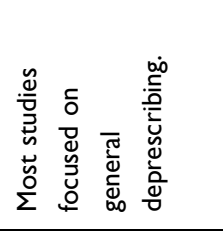 & 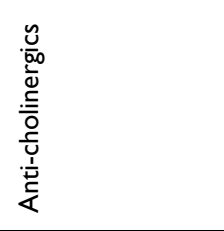 & 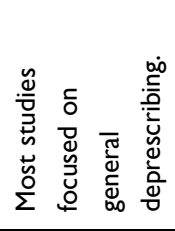 & 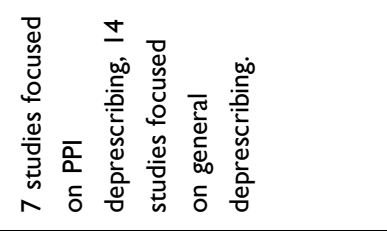 \\
\hline 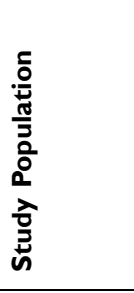 & 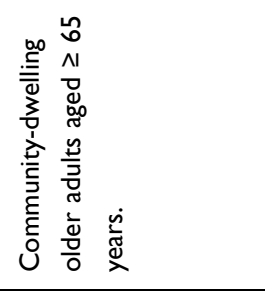 & 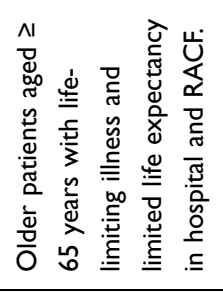 & 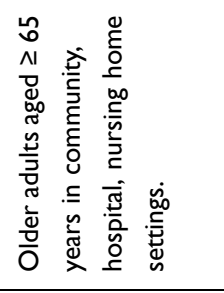 & 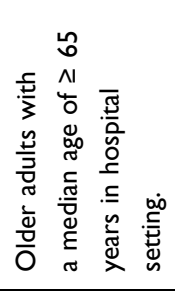 & 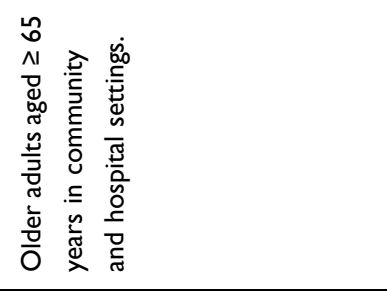 \\
\hline 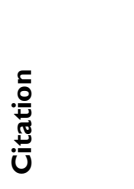 & 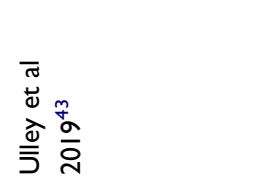 & 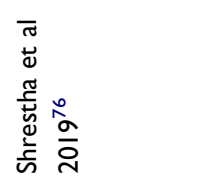 & 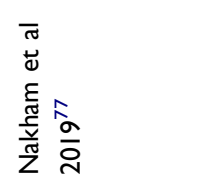 & 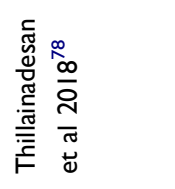 & 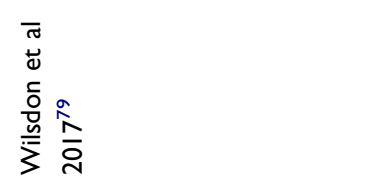 \\
\hline
\end{tabular}




\begin{tabular}{|c|c|c|}
\hline 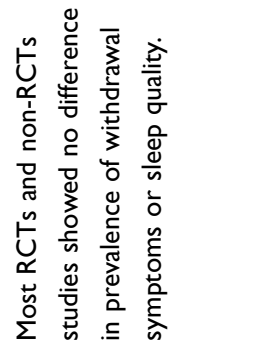 & 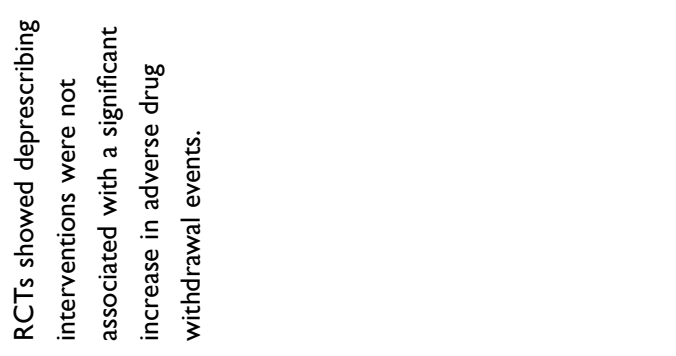 & 号 \\
\hline$\frac{\alpha}{Z}$ & 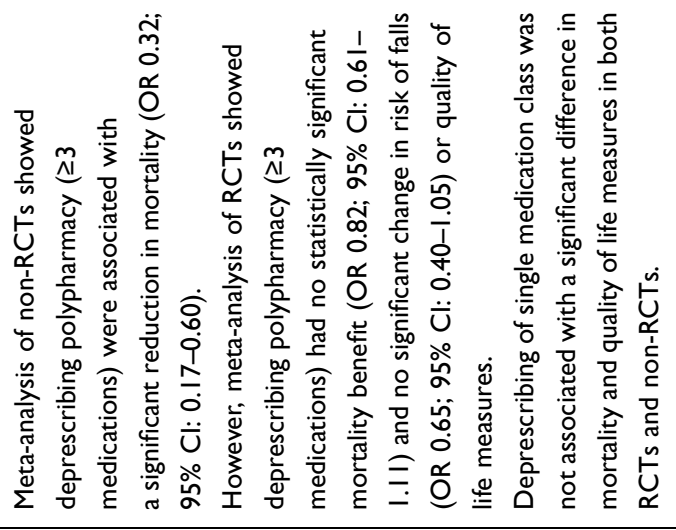 & 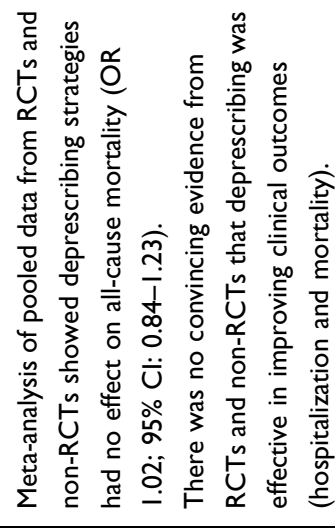 \\
\hline 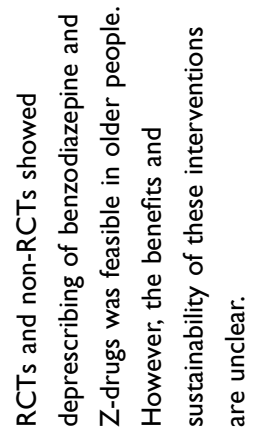 & 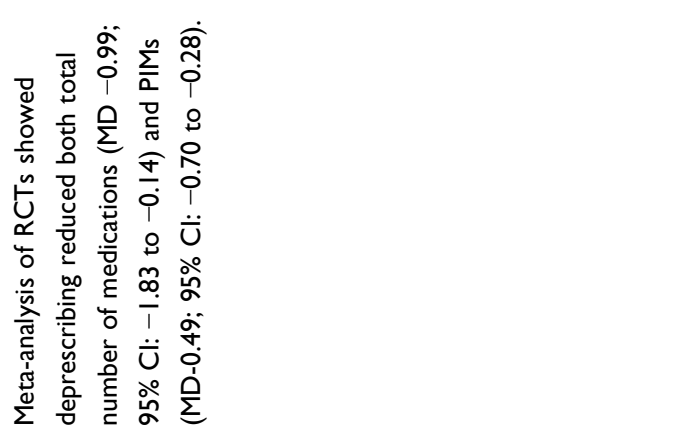 & 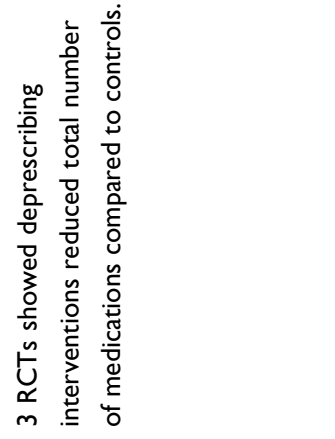 \\
\hline 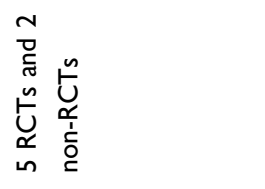 & 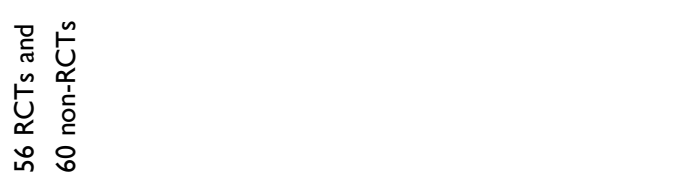 & 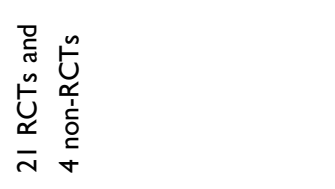 \\
\hline 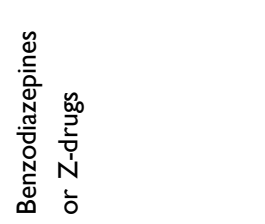 & 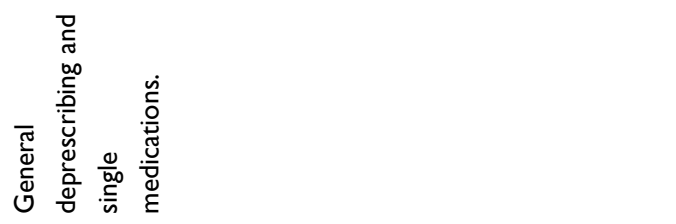 & 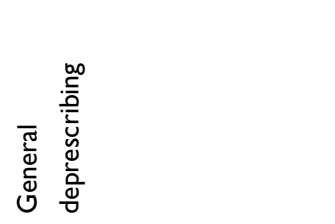 \\
\hline 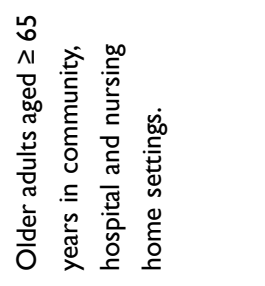 & 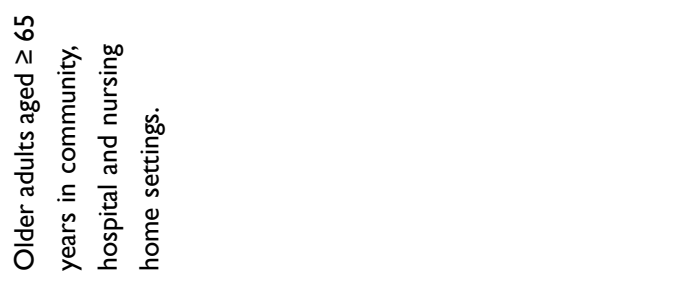 & 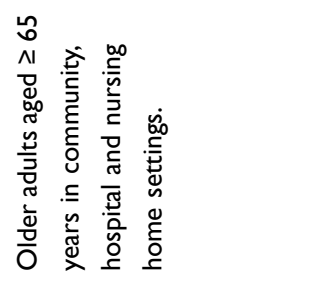 \\
\hline 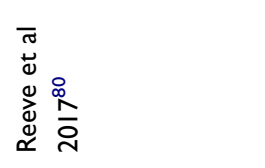 & 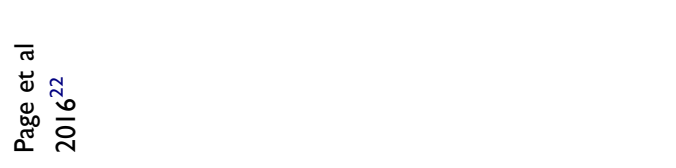 & 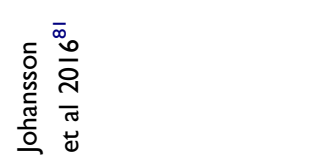 \\
\hline
\end{tabular}


Recently, preclinical studies have sought to fill this knowledge gap by determining the impact of polypharmacy and deprescribing on geriatric outcomes. ${ }^{15-17}$ The first polypharmacy mouse model found that administration of therapeutic doses of five drugs (metoprolol, simvastatin, omeprazole, paracetamol and citalopram) for 4 weeks impaired physical function in old but not young male mice. ${ }^{16}$ A subsequent study found that 4-6 weeks of polypharmacy with a higher anticholinergic and sedative load (metoprolol, simvastatin, oxycodone, oxybutynin and citalopram) impaired physical function in young and old male and female mice, with greater effects in old age, and greater reduction in grip strength in males. ${ }^{15}$ Polypharmacy for 8 weeks (metoprolol, simvastatin, paracetamol, aspirin and citalopram) in young male mice reduced exploration and spatial working memory. ${ }^{18}$ A longitudinal study of treatment from middle to old age, found that polypharmacy regimens with increasing Drug Burden Index ${ }^{19}$ (a measure of cumulative exposure to drugs with anticholinergic and sedative effects) impaired physical function in old male mice, which was attenuated by deprescribing. ${ }^{17}$ This evidence that polypharmacy with high Drug Burden Index causes impaired function in old age, which is reversible with deprescribing, helps to fill the evidence gap on causation and provides a platform for future studies investigating mechanisms, such as complex drug interactions and the effects on aging biology.

\section{Challenges of Deprescribing Studies and Proposed Solutions}

Existing studies exploring the outcomes of deprescribing can be broadly categorized as experimental or observational studies. ${ }^{20-22}$ Whilst deprescribing generally appears to be a safe process, there are potential harms, such as return of the condition that was being treated or presence of withdrawal symptoms. Therefore, it is important that deprescribing is closely supervised and informed by the latest evidence. ${ }^{20,22,23}$ Interpreting and applying this evidence, and designing future studies to fill the gaps, requires an understanding of the challenges of existing research and the potential solutions for future studies. These challenges can be divided into challenges relating to patients, relating to healthcare professionals and arising from the current healthcare system structure. Key challenges and potential solutions are outlined below and summarized in Table 2.

\section{Deprescribing Research: Issues for}

\section{Patients/Consumers}

Deprescribing studies have explored outcomes such as mortality and hospitalization, based on clinician preferences. $^{24,25}$ Previous research has however shown potential discordance between clinician and patient prioritization of different outcomes of therapy. ${ }^{24,26,27}$ As a result, it is important for future deprescribing studies to assess deprescribing outcomes based on both patient and clinician preferences. ${ }^{21,24}$ Based on existing research, it is also unclear how to best educate patients on the effects of deprescribing, which is essential for shared decision making. ${ }^{22}$ Future studies should explore the acceptability and effectiveness of different educational programs on deprescribing and how to best tailor these to different patient populations with different levels of health literacy, comorbidities and concurrent medications. ${ }^{22}$

\section{Deprescribing Research: Issues for Healthcare Professionals}

One of the challenges of existing deprescribing studies for healthcare professionals is the lack of sufficiently powered randomized controlled trials (RCTs) assessing the longterm benefits, safety and sustainability of deprescribing interventions. ${ }^{22-24,28}$ Most studies assess outcomes such as the feasibility and tolerability of deprescribing or reduction in the number of medications, instead of long-term clinical outcomes. ${ }^{22-25}$ Studies do not always explicitly specify the deprescribing schedule used, monitoring or management of patients, making it unclear how to deprescribe those drugs in practice. ${ }^{22}$ There is a need for information on how to manage adverse drug withdrawal effects, reversal of drug-drug interactions ${ }^{21}$ and provision of alternative non-pharmacological or pharmacological therapy after deprescribing. ${ }^{25}$ Well powered RCTs with detailed reporting of the intervention and long-term follow-up of clinical outcomes are needed. ${ }^{22-25,28}$

Studies have explored deprescribing single drug classes, such as benzodiazepines, antipsychotics, antihypertensives and opioids, but patients in practice take a range of other medications. ${ }^{22}$ Existing studies do not always explicitly specify concurrent medications and chronic conditions present, nor do they consistently account for these potential confounders, making it difficult to apply available evidence to multimorbid patients with polypharmacy seen in clinical practice. $^{26,29,30}$ Additionally, patient populations such as palliative care 
Table 2 Summary of Challenges of Existing Deprescribing Research and Potential Solutions for Future Studies

\begin{tabular}{|c|c|c|}
\hline & Challenges & Potential Solutions \\
\hline \multirow[t]{2}{*}{ Patients } & $\begin{array}{l}\text { Assessing deprescribing outcomes based on clinician } \\
\text { preferences. }{ }^{24,25}\end{array}$ & $\begin{array}{l}\text { Involving patients in all phases of research including defining } \\
\text { relevant outcomes, using patient reported outcome } \\
\text { measures, and using individualized goal attainment scale } \\
\text { outcomes. }{ }^{21,24}\end{array}$ \\
\hline & Unclear how to best educate patients about deprescribing. ${ }^{22}$ & $\begin{array}{l}\text { Exploring the acceptability and effectiveness of different } \\
\text { educational programs on deprescribing and how to best tailor } \\
\text { these to different patient populations such as patients with } \\
\text { different levels of health literacy. }{ }^{22}\end{array}$ \\
\hline \multirow{6}{*}{$\begin{array}{l}\text { Healthcare } \\
\text { Professionals }\end{array}$} & \multicolumn{2}{|l|}{ Data on clinical outcomes } \\
\hline & $\begin{array}{l}\text { Lack of sufficiently powered RCTs assessing long-term } \\
\text { deprescribing benefits, safety and sustainability. }{ }^{22-24,28} \\
\text { Existing studies assessing outcomes such as the feasibility of } \\
\text { deprescribing or reduction in the medicines count instead of } \\
\text { clinical outcomes. }{ }^{22-25}\end{array}$ & $\begin{array}{l}\text { Large RCTs with long-term follow-up assessing prescribing } \\
\text { and clinical outcomes and outlining the deprescribing } \\
\text { protocols used. }\end{array}$ \\
\hline & \multicolumn{2}{|l|}{ Detail reported in methods of exiting studies } \\
\hline & $\begin{array}{l}\text { Deprescribing schedule not explicitly reported. }{ }^{22} \\
\text { Management of patients during deprescribing such as } \\
\text { withdrawal symptoms not outlined. }{ }^{25}\end{array}$ & $\begin{array}{l}\text { Practical guidance regarding appropriate management during } \\
\text { deprescribing, including providing safer alternatives such as } \\
\text { nonpharmacological therapy. }{ }^{25}\end{array}$ \\
\hline & \multicolumn{2}{|l|}{ Generalizability to Clinical Practice } \\
\hline & $\begin{array}{l}\text { Range of drug classes seen in clinical practice not explored for } \\
\text { deprescribing. } \\
\text { Not specifying comorbidities and concurrent medications and } \\
\text { not accounting for these potential confounders. }{ }^{26,29,30} \\
\text { Excluding patient populations such as palliative care. }{ }^{20,30}\end{array}$ & $\begin{array}{l}\text { Deprescribing different drug classes seen in practice, in } \\
\text { different patient populations and explicitly specifying } \\
\text { characteristics such as frailty, comorbidities and concurrent } \\
\text { medications, adjusting for any potential } \\
\text { confounders. }^{20,22,29,30,82}\end{array}$ \\
\hline \multirow[t]{3}{*}{$\begin{array}{l}\text { Health } \\
\text { Organizations }\end{array}$} & $\begin{array}{l}\text { Large, robust studies assessing cost-effectiveness of } \\
\text { deprescribing interventions, including models of care with } \\
\text { time specifically dedicated to deprescribing are limited. }{ }^{25,28} \\
\text { Healthcare organizations undertake deprescribing research as } \\
\text { separate groups nationally and internationally. }{ }^{25}\end{array}$ & $\begin{array}{l}\text { More studies exploring cost-effectiveness of different } \\
\text { deprescribing interventions, including models of care with } \\
\text { dedicated time for deprescribing. }{ }^{25} \\
\text { Collaboration between different healthcare organizations to } \\
\text { increase capacity to undertake large deprescribing trials. }\end{array}$ \\
\hline & $\begin{array}{l}\text { Electronic healthcare systems do not always include } \\
\text { deprescribing prompts embedded into them. } .^{31,32}\end{array}$ & $\begin{array}{l}\text { Exploring deprescribing interventions embedded into } \\
\text { electronic healthcare management systems. }{ }^{31,32}\end{array}$ \\
\hline & $\begin{array}{l}\text { Studies exploring specific roles of different healthcare } \\
\text { disciplines during the deprescribing process are limited. }\end{array}$ & $\begin{array}{l}\text { More research to understand specific roles of different health } \\
\text { disciplines which may help develop streamlined, efficient } \\
\text { processes around deprescribing. }{ }^{28}\end{array}$ \\
\hline
\end{tabular}

are often excluded from studies, whereas these patients have high uncertainty regarding the benefits of continuing medications. ${ }^{20,30}$ Therefore, there is a need for future research to explore deprescribing different drug classes seen in practice, in different patient populations and explicitly specify characteristics of the study population such as medical conditions and concurrent medications, adjusting for any potential confounders. ${ }^{20,22,25,29,30}$

\section{Deprescribing Research: Issues for Current Healthcare Systems}

Deprescribing interventions can be time-consuming and resource-intensive in addition to the ongoing cost of using different medications. ${ }^{28}$ Deprescribing harmful medications may however result in potential cost savings such as less visits to the general practitioner and reduced number of hospitalizations. ${ }^{28}$ Large, robust studies exploring cost- 
effectiveness of different deprescribing interventions are limited. $^{28}$ Therefore, more research is needed exploring the cost-effectiveness of different deprescribing interventions. ${ }^{25}$ The current healthcare structure does not include time specifically dedicated during medical appointments to explore deprescribing. ${ }^{25}$ Future studies may explore models of care with time during each appointment specifically dedicated to discuss deprescribing options. ${ }^{25}$

The shift towards using electronic healthcare systems globally, presents the opportunity for future studies to explore deprescribing interventions embedded into electronic systems. ${ }^{31,32}$ Whilst medication management involves different healthcare disciplines such as medical practitioners, pharmacists and nurses, more research is necessary to understand specific roles of different disciplines which may help develop streamlined, efficient, multidisciplinary processes around deprescribing. ${ }^{28}$
Different healthcare organizations undertake deprescribing research as separate groups nationally and internationally, resulting in unnecessary research duplication and lack of sharing of findings. ${ }^{25}$ Future studies should consider collaboration between different healthcare organizations. Deprescribing networks, which have emerged internationally since the first was established in Australia in 2014, should ideally increase capacity to undertake large trials and help address the different challenges of existing studies. $^{25,33}$

\section{Implementation Challenges: Patients, Healthcare Professionals and Healthcare Systems}

In addition to the knowledge gaps in deprescribing research, implementation of deprescribing in clinical practice faces many challenges at patient, healthcare professional and healthcare system levels (Figure 1). At the

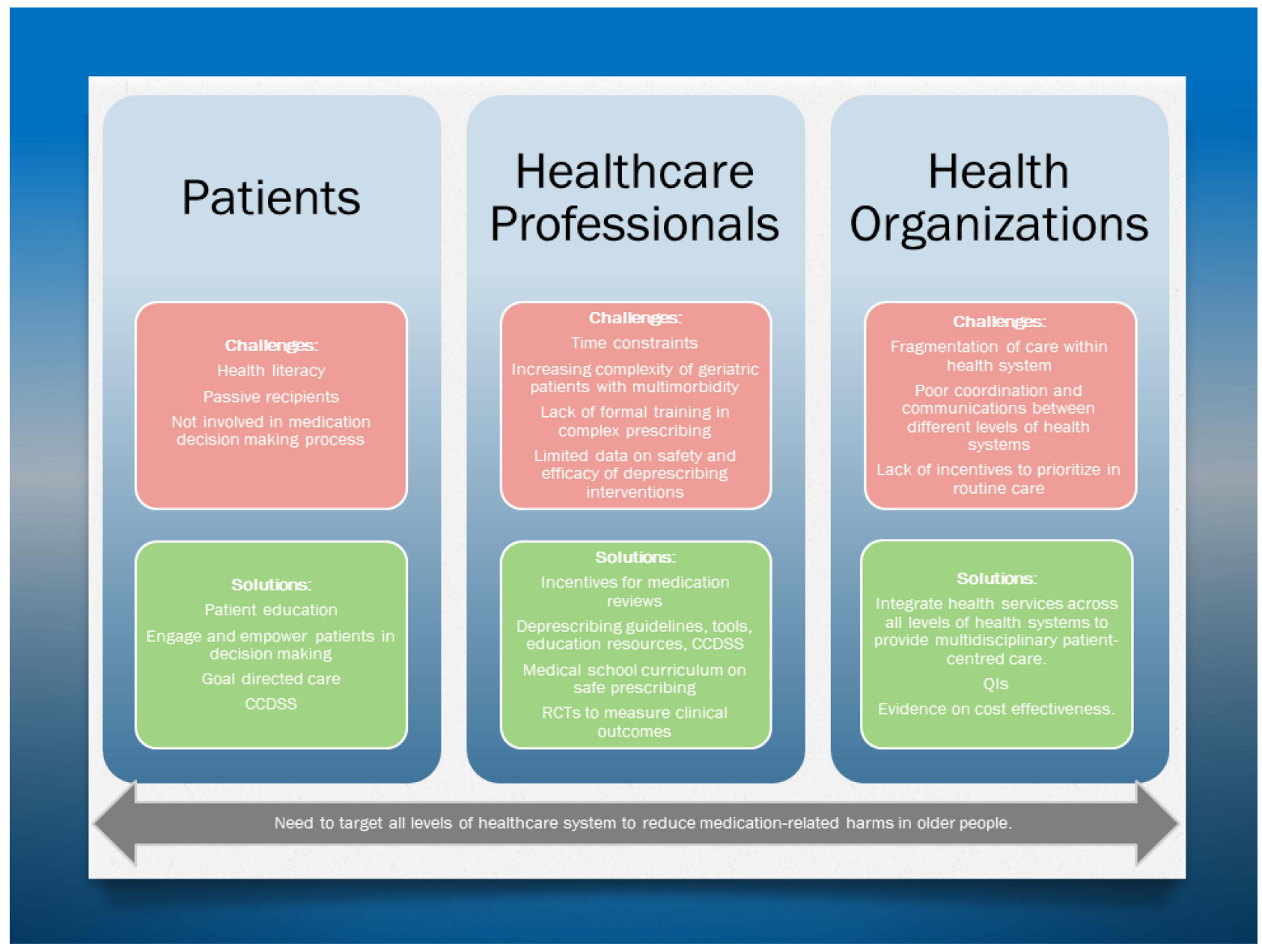

Figure I Deprescribing challenges and their solutions across different levels of healthcare system, informed by multiple sources. ${ }^{36,38}$ Abbreviations: CCDSS, Computerized Clinical Decision Support Systems; QIs, Quality Indicators 
patient level, people may have limited health literacy and false beliefs that medications are always superior to nonpharmacological approaches in treating diseases. Patients and/or their carers may be resistant to stop medications that they have been taking for a long time due to unrealistic expectations in the efficacy of the medications. ${ }^{34}$ Other patient level challenges to deprescribing include lack of knowledge of the potential side effects of the medications and socioeconomic factors, where access to regular health services may be limited. ${ }^{34,35}$ At the healthcare professional level, the increasing complexity of older patients as a result of multimorbidity and polypharmacy can pose challenges for medical practitioners to distinguish between medication side effects and new complaints. Often, inadequate time is spent on reviewing patient's medication list. ${ }^{36}$ On the other hand, clinical inertia or reluctance to talk to patients about therapy appropriateness, ${ }^{37}$ reluctance to interfere with management initiated by other healthcare professionals, and lack of formal training in prescribing for older people have been identified as a potential barriers to deprescribing. At the healthcare system level, there can be issues with fragmentation of care, ${ }^{38}$ difficulty accessing patient's health information and poor coordination and communication between specialists and general practitioners when medications are initiated, changed or ceased. ${ }^{39}$

\section{Implementation Solutions: Patient, Healthcare Professional and Healthcare System}

Given the growing burden of medication-related problems in older people, and the complexity of deprescribing process, the success of deprescribing interventions depends on simultaneous strategies and policies across all levels (Figure 1, Table 3), involving patients and the public, healthcare professionals, health organizations, regulatory and policymakers. Patient education and improvement in health literacy are potential strategies to help patient develop realistic expectations about their health treatment. Physicians and other healthcare professionals can provide suitable evidence-based advice about benefits and harms of each medication the patient is taking. These strategies are likely to be more effective if delivered using a patient-centered approach. ${ }^{40}$ It is important that treating physicians understand patient's preferences and goals of care, and how they can contribute to improving clinical outcomes through goal-directed medication reviews.

Table 3 Summary of Challenges and Solutions of Implementing Deprescribing in the Healthcare System, Data from Multiple Sources $^{36,38}$

\begin{tabular}{|c|c|c|}
\hline & Challenges & Solutions \\
\hline Patients & $\begin{array}{l}\text { Poor health literacy, reluctant to discontinue medications due } \\
\text { to false belief. } \\
\text { Patients are often passive recipients of medications, not } \\
\text { involved in the decision making process on the use of } \\
\text { medications. }\end{array}$ & $\begin{array}{l}\text { Provide educational materials and tools (eg patient-held } \\
\text { medication record, medication passport) to enhance patient } \\
\text { awareness about inappropriate polypharmacy and understand } \\
\text { the benefits and harms of each medication. } \\
\text { Engage and empower patients to play an active role in their } \\
\text { health care, so they can safely manage their own medications. }\end{array}$ \\
\hline $\begin{array}{l}\text { Healthcare } \\
\text { Professionals }\end{array}$ & $\begin{array}{l}\text { Increasing number of complex geriatric patients with } \\
\text { multimorbidity. } \\
\text { Lack of formal training in prescribing for older patients with } \\
\text { complex polypharmacy. } \\
\text { Time constraints to counsel patients on medication-related } \\
\text { harms. }\end{array}$ & $\begin{array}{l}\text { Provide health professionals with tools, guidelines and } \\
\text { educational resources on how to manage polypharmacy in } \\
\text { older people. } \\
\text { Develop educational curricula on safe medication } \\
\text { management and deprescribing for both undergraduate and } \\
\text { postgraduate health professionals. } \\
\text { Provide additional incentives to health professionals that } \\
\text { conduct a medication regimen review as part of routine } \\
\text { health check-up. }\end{array}$ \\
\hline $\begin{array}{l}\text { Health } \\
\text { Organizations }\end{array}$ & $\begin{array}{l}\text { Healthcare systems and practices of medication are often } \\
\text { complex and dysfunctional. Fragmentation of care within } \\
\text { healthcare system. } \\
\text { Poor coordination and communication between different } \\
\text { health professionals (eg specialists and general practitioners) } \\
\text { when new medications are initiated. }\end{array}$ & $\begin{array}{l}\text { Integrate health services across all levels of healthcare } \\
\text { systems to provide multidisciplinary patient-centered care. } \\
\text { Establish a national deprescribing working group of leading } \\
\text { experts, regulators and policymakers to develop strategies, } \\
\text { guidelines and action plans on polypharmacy and } \\
\text { deprescribing in older people. }\end{array}$ \\
\hline
\end{tabular}


Continued involvement of patients throughout the deprescribing process has been shown to be instrumental in improving the success of deprescribing interventions. ${ }^{41}$ There are opportunities to include deprescribing in the evidence-based recommendations in the 4Ms Framework for an Aged-Friendly Health System that aims to align what matters to the older patients and their family caregivers with their medications, mentation and mobility. ${ }^{42}$ Potential advantage in adherence maybe another incentive for implementation. ${ }^{43}$ At healthcare professional level, deprescribing requires a close interdisciplinary collaboration between the general practitioners, physicians, pharmacists, nurses and allied health professionals. This multidisciplinary care approach is likely to provide the most optimal management of patient's medication regimen based on consensus from all healthcare professionals involved. ${ }^{36}$ In addition, hospital-based initiatives aimed to improve awareness and skills of clinicians and pharmacists through provision of deprescribing protocols, and use of explicit criteria to guide medication review have proven to be effective in achieving deprescribing. ${ }^{44,45}$ Introducing prescribing education in medical schools and continuing medical education programs for health professionals can improve the skills and confidence of healthcare professionals managing medication-related problems in older people. $^{36,46,47}$ At the healthcare system level, specialist medical colleges and other professional and consumer groups have important roles in advocacy and can influence policies related to health literacy and coordination between primary, secondary and tertiary health care providers. Therefore, a concerted effort from all levels of healthcare systems will be needed to make a significant impact on reducing inappropriate medication use.

\section{Implementation Solutions: Computerized Clinical Decision Support Systems}

Computerized Clinical Decision Support Systems (CCDSS) are defined as multiple integrated systems that can apply algorithms to individual patient data to generate suggested actions intended to improve or support clinical decision-making for healthcare practitioners. ${ }^{48}$ CCDSS are considered to be one of the many solutions to optimising prescribing of medications and medication safety in older adults. ${ }^{49}$ The types of CCDSS can vary, from simple electronic medical record alerts directed towards healthcare practitioners at the point of prescribing or medication review, to integrated complex features such as recommending a medication for deprescribing or substituting for a therapeutic equivalent. The success of CCDSS interventions in deprescribing relies on the design, user interface and integration into practice. A systematic review of the features of effective CCDSS interventions identified that successful interventions included systems that required practitioners to provide reasons when overriding advice, and systems that were designed to provide advice to the patient and practitioner simultaneously, allowing for a person-centered focus of care. ${ }^{50}$ However, many interventional studies poorly describe the CCDSS design and implementation features, which may hinder future development of successful CCDSS interventions focused on deprescribing inappropriate medications.

Many systematic reviews have been conducted to specifically assess whether CCDSS are a successful solution to deprescribing medications in older adults (Table 4). Monteiro et al aimed to evaluate the evidence of CCDSS to address polypharmacy and prevent its occurrence. ${ }^{51}$ In this review, almost all studies reported that the CCDSS interventions reduced the number of PIMs that were deprescribed or improved medication appropriateness, however, statistical significance was not always achieved.

In a systematic review that aimed to evaluate the effectiveness, comparative effectiveness, and harms of deprescribing interventions among community-dwelling older adults, four trials were identified that evaluated the effect of CCDSS. ${ }^{52}$ These trials were conducted in the USA and Canada, and only two out of the four trials reported a significant reduction of potentially inappropriate medications in the intervention group compared with the control group.

A systematic review conducted in 2018 examined the evidence for efficacy of CCDSS designed to reduce potentially inappropriate prescribing in hospitalized older adults. ${ }^{53}$ This review found that seven out of the eight studies included demonstrated a statistically significant reduction in the proportion of patients prescribed an inappropriate medication; however, interpretation of the results was discussed given the limitations of generalizability of the studies and single-center studies.

Iankowitz et al examined the effect of CCDSS on the frequency of prescribing potentially inappropriate medications at discharge and related unplanned hospitalizations. ${ }^{54}$ The authors concluded that although CCDSS had the potential for decreasing the number of potentially inappropriate medications in older adults, conclusions about unplanned hospitalizations could not be made, given the lack of evidence. 
Overall, although many systematic reviews have demonstrated that CCDSS interventions can affect deprescribing inappropriate medications in older adults, there are no reviews that provide evidence on CCDSS interventions on clinical outcomes, such as falls, frailty, quality of life or mortality.

\section{Implementation Solutions: Quality Indicators}

Another example of a key implementation tool is the use of Quality Indicators (QIs). QIs are a recognized mechanism for improving quality use of medicines if they have been robustly developed and their measurement properties scientifically tested. ${ }^{55}$ QIs are measurable elements of practice performance for which there is evidence or consensus that it can be used to assess the quality, and hence change in the quality, of care provided. ${ }^{56}$ QIs are usually described with a denominator and a numerator. The denominator is the total number of cases in the intended population, and the numerator is the number of cases in the denominator that fulfil a predetermined criterion, and the calculated QI score indicates the quality of care. QIs can be used for monitoring process performance, assessing quality improvement activities, providing feedback to

Table 4 Summary of Systematic Reviews to Evaluate Computerized Clinical Decision Support Systems (CCDSS) in Deprescribing in Older Adults

\begin{tabular}{|c|c|c|c|c|c|c|}
\hline Citation & $\begin{array}{l}\text { Study } \\
\text { Population }\end{array}$ & $\begin{array}{l}\text { Deprescribing } \\
\text { Target }\end{array}$ & $\begin{array}{l}\text { Number } \\
\text { and Type } \\
\text { of } \\
\text { Studies }\end{array}$ & $\begin{array}{l}\text { Impact on Medication } \\
\text { Use* }\end{array}$ & $\begin{array}{l}\text { Impact on Global Health } \\
\text { Outcomes (Mortality, } \\
\text { Hospitalization, Geriatric } \\
\text { Syndromes)* }\end{array}$ & $\begin{array}{l}\text { Adverse } \\
\text { Drug } \\
\text { Withdrawal } \\
\text { Effects* }\end{array}$ \\
\hline $\begin{array}{l}\text { Bloomfield } \\
\text { et al } \\
2020^{52}\end{array}$ & $\begin{array}{l}\text { Community- } \\
\text { dwelling } \\
\text { older adults } \\
\text { aged } \geq 65 \\
\text { years. }\end{array}$ & $\begin{array}{l}\text { Most studies } \\
\text { focused on } \\
\text { general } \\
\text { deprescribing. }\end{array}$ & 4 RCTs & $\begin{array}{l}2 \text { studies reported reduction } \\
\text { in PIMs in the intervention } \\
\text { group, and } 2 \text { reported no } \\
\text { effect. }\end{array}$ & NR & NR \\
\hline $\begin{array}{l}\text { Monteiro } \\
\text { et al } \\
2019^{51}\end{array}$ & $\begin{array}{l}\text { Older adults } \\
\text { aged } \geq 65 \\
\text { years in } \\
\text { community } \\
\text { and hospital } \\
\text { settings. }\end{array}$ & $\begin{array}{l}\text { General } \\
\text { deprescribing } \\
\text { and single } \\
\text { medications. }\end{array}$ & $\begin{array}{l}\text { I0 RCTs } \\
\text { and } 6 \\
\text { non-RCTs }\end{array}$ & CCDSS may reduce PIMs. & NR & NR \\
\hline $\begin{array}{l}\text { Dalton } \\
\text { et al } \\
2018^{53}\end{array}$ & $\begin{array}{l}\text { Older adults } \\
\text { aged } \geq 65 \\
\text { years in } \\
\text { hospital } \\
\text { setting. }\end{array}$ & $\begin{array}{l}\text { General } \\
\text { deprescribing } \\
\text { and single } \\
\text { medications. }\end{array}$ & $\begin{array}{l}2 \text { RCTs } \\
\text { and } 6 \\
\text { non-RCTs }\end{array}$ & $\begin{array}{l}\text { Intervention patients were } \\
\text { less likely to be prescribed } \\
\text { a PIM (OR 0.6; } 95 \% \mathrm{Cl}: 0.38 \\
-0.93 \text { ) }\end{array}$ & $\begin{array}{l}\text { Most studies did not assess } \\
\text { global health outcomes such } \\
\text { as falls, hospitalization or } \\
\text { mortality. One non-RCT } \\
\text { study showed CCDSS } \\
\text { resulted in a statistically } \\
\text { significant reduction in } \\
\text { inpatient falls. }\end{array}$ & NR \\
\hline $\begin{array}{l}\text { lankowitz } \\
\text { et al } \\
2012^{54}\end{array}$ & $\begin{array}{l}\text { Older adults } \\
\text { aged } \geq 65 \\
\text { years in } \\
\text { community } \\
\text { and hospital } \\
\text { settings. }\end{array}$ & $\begin{array}{l}\text { General } \\
\text { deprescribing } \\
\text { and single } \\
\text { medications. }\end{array}$ & $\begin{array}{l}4 \text { RCTs } \\
\text { and I } \\
\text { non-RCTs }\end{array}$ & $\begin{array}{l}\text { CCDSS had the potential for } \\
\text { decreasing the number of } \\
\text { PIMs, conclusions about } \\
\text { unplanned hospitalizations } \\
\text { could not be made. } \\
\text { The computer systems were } \\
\text { significantly effective in } \\
\text { decreasing frequency of } \\
\text { ordering PIMs. }\end{array}$ & NR & NR \\
\hline
\end{tabular}

Notes: * Specific numerical data in the forms of odds ratio (OR), risk ratio (RR) or mean difference (MD) and $95 \%$ confidence interval are only reported if the study has performed meta-analyses of the outcomes of interest.

Abbreviations: RCT, randomized controlled trial; c-RCT, cluster randomized controlled trial; CCDSS, computerized clinical decision support systems; NR, not reported; PIMs, potentially inappropriate medications; OR, odds ratio; $\mathrm{Cl}$, confidence intervals. 
healthcare providers, assisting patients in choosing their providers, or detecting unsafe situations. Therefore, the purpose of QIs could vary depending on the stakeholders (eg patients, practitioners, payers, healthcare inspectorate, researchers, or governments).

More than 2400 content validated medication-related QIs exist covering most diseases and conditions. ${ }^{57}$ These QIs for measuring adherence to medication guideline could be applied to minimize potentially inappropriate medications (eg \% of persons age $65+$ years prescribed antidepressants using an anticholinergic antidepressant drug). ${ }^{58}$ In addition, QIs for polypharmacy management were developed and implemented in some countries. For example, Swedish Indicators for Quality of Drug Therapy in Older Persons includes three polypharmacy management indicators (eg \% of persons age $75+$ years prescribed ten or more drugs). ${ }^{59}$ NHS Scotland published one polypharmacy indicator and six high risk prescribing indicators for the older person (eg $\%$ of persons age $75+$ years prescribed an antipsychotic drug). ${ }^{60}$ In Australia, a set of QIs for reducing inappropriate polypharmacy (ie, polypharmacy QUM indicators) was developed by a team led by the authors (Table 5). ${ }^{61}$ The polypharmacy QUM indicators are designed to evaluate processes involved in identification of medication-related harm in older hospitalized patients and the management of inappropriate polypharmacy. Specifically, of the seven polypharmacy QUM indicators, three QIs are related to the identification of older patients at high risk of medication-related harm, one QI to the implementation of hospital-based medication review, and three QIs to optimising discharge communications and continuation of medication care at transitions of care. As causes of inappropriate polypharmacy could vary, a combination approach using the seven QIs is important.

To stimulate continuous quality improvement activities, QI scores are tied to financial incentives, ${ }^{62}$ public reporting, ${ }^{63}$ quality management accreditation, ${ }^{64}$ or continued professional development. ${ }^{65}$ Note that the use of QIs also has the potential for unintended negative consequences. These consequences are likely to become prominent when QIs are linked with financial incentives. ${ }^{66}$ In such a case, data manipulation could occur to reach predetermined threshold values. In addition, healthcare institutions may turn away specific types of patients who may decrease QI scores. Furthermore, under pay-for-performance models, institutions may focus only on the quality of care linked with financial incentives and pay less attention to the quality of care
Table 5 New South Wales Therapeutic Advisory Group (NSW TAG) Polypharmacy Quality Use of Medicines (QUM) Indicators ${ }^{83}$

\begin{tabular}{|c|}
\hline $\begin{array}{l}\text { Identification of Older Patients at High Risk of Medication- } \\
\text { Related Harm }\end{array}$ \\
\hline $\begin{array}{l}\text { I. Percentage of older patients that are appropriately assessed for risk } \\
\text { of harm from inappropriate polypharmacy } \\
\text { 2. Percentage of older patients that are appropriately assessed for risk } \\
\text { of medication-related falls } \\
\text { 3. Percentage of older patients that are appropriately assessed for risk } \\
\text { of medication-related impairment of cognitive and/or physical function }\end{array}$ \\
\hline Intervention: a hospital-based medication review (HBMR) \\
\hline $\begin{array}{l}\text { 4. Percentage of older patients at high risk of medication-related } \\
\text { harms that receive a hospital-based medication review and, if } \\
\text { applicable, a deprescribing plan }\end{array}$ \\
\hline $\begin{array}{l}\text { Optimising discharge communications and continuation of } \\
\text { medication care at transitions of care }\end{array}$ \\
\hline $\begin{array}{l}\text { 5. Percentage of older patients at high risk of medication-related } \\
\text { harms with a recommendation for a post-discharge medication } \\
\text { review, when hospital-based medication review is not performed } \\
\text { 6. Percentage of older patients whose discharge summaries contain } \\
\text { a current, accurate and comprehensive list of medicines, including } \\
\text { explanations for any medication therapy changes and, if applicable, } \\
\text { details of a deprescribing plan } \\
\text { 7. Percentage of older patients who receive a current, accurate and } \\
\text { comprehensive medication list, including explanations for any } \\
\text { medication changes and, if applicable, details of a deprescribing plan, } \\
\text { at the time of hospital discharge }\end{array}$ \\
\hline
\end{tabular}

Notes: Reproduced with permission from New South Wales Therapeutic Advisory Group (NSW TAG) Polypharmacy Quality Use of Medicines (QUM) Indicators. Available from: https://www.nswtag.org.au/qum-indicators/ Accessed May 6, 2021. (c) NSW Therapeutic Advisory Group Inc $2020 .^{83}$

not being measured. It is not surprising that some healthcare providers do not welcome the use of QIs for fear of being judged or blamed for their poor performance. ${ }^{67}$ Hence, the users of QIs should be aware of which aspects of care are not being measured, and of these unintended negative consequences.

When using QIs, standardized data collection systems are expected to be established so that QIs can be measured automatically using routine clinical practice data sets. These systems will also be of importance for reducing the burden of data collection, assuring data accuracy, linking to other routine data, and enabling real-time decision support. Given the dynamic nature of healthcare, ongoing quality improvement activities, using methodology such as the Plan-Do-Study-Act cycles, are expected to facilitate deprescribing inappropriate polypharmacy. 
There are several limitations in our review merit comments. First, this is not a systematic review of systematic reviews, as we have not followed the protocol of a systematic review. ${ }^{68,69}$ Second, we acknowledge the limitations of traditional narrative reviews, such as the risk of bias (publication bias and selection bias), variation in study quality and potential overlapping reviews in the included systematic reviews have not been rigorously accounted for. ${ }^{70-73}$

\section{Conclusions}

Inappropriate medication use contributes to significant morbidity and mortality in older people. Deprescribing is an established management strategy to minimize polypharmacy and potentially inappropriate medications. Knowledge of the efficacy of deprescribing polypharmacy on clinical outcomes in older patients is limited. This has recently been supplemented by preclinical data, demonstrating that deprescribing in old age attenuates frailty and functional impairment caused by chronic polypharmacy. The benefits and sustainability of deprescribing interventions on long-term quality of life, morbidity and geriatric outcomes in older people remain unclear. Various patient level, healthcare professional level and healthcare system level challenges influence the success of deprescribing studies and implementation. Researchers, healthcare professionals and policymakers have a great responsibility to promote quality use of medication in older people by overcoming these challenges. Deprescribing networks emerging internationally can further facilitate novel research and successful implementation of deprescribing in clinical practice. Future large multicenter prospective studies of deprescribing are needed to establish the efficacy of deprescribing interventions in older populations, and to clarify which subgroups would benefit most from this approach. This will help deprescribing find its place in routine prescribing, under the umbrella of personalized medicine.

\section{Disclosure}

Prof Sarah N Hilmer and Dr Lisa Kouladjian O'Donnell are both members of the executive committee of the Australian Deprescribing Network (voluntary roles). The authors report no other conflict of interest in this work.

\section{References}

1. Charlesworth CJ, Smit E, Lee DS, Alramadhan F, Odden MC. Polypharmacy among adults aged 65 years and older in the United States: 1988-2010. J Gerontol A Biol Sci Med Sci. 2015;70:989-995. doi:10.1093/gerona/glv013
2. Hilmer SN, Gnjidic D. The effects of polypharmacy in older adults. Clin Pharmacol Ther. 2009;85:86-88. doi:10.1038/clpt.2008.224

3. Hilmer SN, Wu H, Zhang M. Biology of frailty: implications for clinical pharmacology and drug therapy in frail older people. Mech Ageing Dev. 2019;181:22-28. doi:10.1016/j.mad.2019.111119

4. Gnjidic D, Hilmer SN, Blyth FM, et al. High-risk prescribing and incidence of frailty among older community-dwelling men. Clin Pharmacol Ther. 2012;91:521-528. doi:10.1038/clpt.2011.258

5. Gnjidic D, Hilmer SN, Blyth FM, et al. Polypharmacy cutoff and outcomes: five or more medicines were used to identify community-dwelling older men at risk of different adverse outcomes. J Clin Epidemiol. 2012;65:989-995. doi:10.1016/j. jclinepi.2012.02.018

6. Wu H, Mach J, Le Couteur DG, Hilmer SN. Fall-related mortality trends in Australia and the United Kingdom: implications for research and practice. Maturitas. 2020;142:68-72. doi:10.1016/j. maturitas.2020.07.008

7. Wu H, Mach J, Le Couteur DG, Hilmer SN. Nationwide mortality trends of delirium in Australia and the United States from 2006 to 2016. Australas J Ageing. 2021. doi:10.1111/ajag.12926

8. Wu H, Le Couteur DG, Hilmer SN. Mortality trends of stroke and dementia: changing landscapes and new challenges. J Am Geriatr Soc. 2021. doi: $10.1111 /$ jgs. 17322

9. Waller S. Reducing medication-related harm through quality use of medicines. J Pharm Pract Res. 2020;50:374-376. doi:10.1002/jppr.1692

10. Donaldson LJ, Kelley ET, Dhingra-Kumar N, Kieny MP, Sheikh A. Medication without harm. WHO's third global patient safety challenge. Lancet. 2017;389:1680-1681. doi:10.1016/s0140-6736(17)31047-4

11. Woodward MC. Deprescribing: achieving better health outcomes for older people through reducing medications. $J$ Pharm Pract Res. 2003;33:323-328. doi:10.1002/jppr2003334323

12. Reeve E, Gnjidic D, Long J, Hilmer S, Systematic A. Review of the EMERGING DEfiNITION of 'Deprescribing' with network analysis: implications for future research and clinical practice. $\mathrm{Br} J$ Clin Pharmacol. 2015;80:1254-1268. doi:10.1111/bcp.12732

13. Scott IA, Hilmer SN, Reeve E, et al. Reducing inappropriate polypharmacy: the process of deprescribing. JAMA Intern Med. 2015;175:827-834. doi:10.1001/jamainternmed.2015.0324

14. Brodaty H, Aerts L, Harrison F, et al. Antipsychotic deprescription for older adults in long-term care: the halt study. $J$ Am Med Dir Assoc. 2018;19(592-600.e7). doi:10.1016/j.jamda.2018.05.002

15. Wu H, Mach J, Gemikonakli G, et al. Polypharmacy results in functional impairment in mice: novel insights into age and sex interactions. J Gerontol a Biol Sci Med Sci. 2021. doi:10.1093/gerona/glab088

16. Huizer-Pajkos A, Kane AE, Howlett SE, et al. Adverse geriatric outcomes secondary to polypharmacy in a mouse model: the influence of aging. J Gerontol a Biol Sci Med Sci. 2016;71:571-577. doi:10.1093/gerona/glv046

17. Mach J, Gemikonakli G, Logan C, et al. Chronic Polypharmacy with Increasing Drug Burden Index (Dbi) exacerbates frailty and impairs physical function, with effects attenuated by deprescribing, in aged mice. J Gerontol a Biol Sci Med Sci. 2020. doi:10.1093/gerona/glaa060

18. Eroli F, Johnell K, Latorre Leal M, et al. Chronic polypharmacy impairs explorative behavior and reduces synaptic functions in young adult mice. Aging (Albany N Y). 2020;12:10147-10161. doi:10.18632/aging.103315

19. Hilmer SN. Calculating and using the drug burden index score in research and practice. Expert Rev Clin Pharmacol. 2018;11:1053-1055. doi:10.1080/17512433.2018.1528145

20. Liacos M, Page AT, Etherton-Beer C. Deprescribing in Older People. Aust Prescr. 2020;43:114-120. doi:10.18773/austprescr.2020.033

21. Reeve E, Moriarty F, Nahas R, et al. Review of the safety concerns of deprescribing in older adults and strategies to mitigate potential harms. Expert Opin Drug Saf. 2018;17:39-49. doi:10.1080/ 14740338.2018.1397625 
22. Page AT, Clifford RM, Potter K, Schwartz D, Etherton-Beer CD, Feasibility T. Effect of deprescribing in older adults on mortality and health: a systematic review and meta-analysis. Br J Clin Pharmacol. 2016;82:583-623. doi:10.1111/bcp.12975

23. Thompson W, Farrell B. Deprescribing: what is it and what does the evidence tell us? Can J Hosp Pharm. 2013;66:201-202. doi:10.4212/ cjhp.v66i3.1261

24. Earl TR, Katapodis ND, Schneiderman SR, Shoemaker-Hunt SJ. Using deprescribing practices and the screening tool of older persons' potentially inappropriate prescriptions criteria to reduce harm and preventable adverse drug events in older adults. J Patient Saf. 2020;16:S23-s35. doi:10.1097/pts.0000000000000747

25. Thompson W, Reeve E, Moriarty F, et al. Deprescribing: future directions for research. Res Soc Admin Pharm. 2019;15:801-805. doi:10.1016/j.sapharm.2018.08.013

26. Burghle A, Lundby C, Ryg J, et al. Attitudes Towards Deprescribing among Older Adults with Limited Life Expectancy and Their Relatives: a Systematic Review. Drugs Aging. 2020;37:503-520. doi:10.1007/s40266-020-00774-x

27. Caughey GE, Tait K, Vitry AI, Shakib S. Influence of medication risks and benefits on treatment preferences in older patients with multimorbidity. Patient Prefer Adherence. 2017;11:131-140. doi:10.2147/ppa.S118836

28. Reeve E, Shakib S, Hendrix I, Roberts MS, Wiese MD, Benefits T. Harms of Deprescribing. Med J Aust. 2014;201:386-389. doi: $10.5694 / \mathrm{mja} 13.00200$

29. Doherty AJ, Boland P, Reed J, et al. Barriers and facilitators to deprescribing in primary care: a systematic review. BJGP Open. 2020;4:bjgpopen20X101096. doi:10.3399/bjgpopen20X101096

30. Reeve E, Jordan V, Thompson W, et al. Withdrawal of Antihypertensive Drugs in Older People. Cochrane Database Syst Rev. 2020. doi:10.1002/14651858.CD012572.pub2

31. Scott IA, Pillans PI, Barras M, Morris C. Using Emr-enabled computerized decision support systems to reduce prescribing of potentially inappropriate medications: a narrative review. Ther Advan Drug Saf. 2018;9:559-573. doi:10.1177/2042098618784809

32. Reeve E. Deprescribing tools: a review of the types of tools available to aid deprescribing in clinical practice. J Pharm Pract Res. 2020;50:98-107. doi:10.1002/jppr.1626

33. Australian Deprescribing Network (ADeN). Available from: https:// australiandeprescribingnetwork.com.au/. Accessed May 5, 2021.

34. Reeve E, To J, Hendrix I, Shakib S, Roberts MS, Wiese MD. Patient barriers to and enablers of deprescribing: a systematic review. Drugs Aging. 2013;30:793-807. doi:10.1007/s40266-013-0106-8

35. Reeve E, Low LF, Hilmer SN. Beliefs and Attitudes Of Older Adults And Carers About Deprescribing Of Medications: A Qualitative Focus Group Study. $B r \quad J$ Gen Pract. 2016;66:e552-60. doi:10.3399/bjgp16X685669

36. Quality Use of Medicines to Optimise Ageing in Older Australians. Recommendations for a National Strategic Action Plan to Reduce Inappropriate Polypharmacy. NHMRC Cognitive Decline Partnership Centre, University of Sydney, in Collaboration with the Australian Deprescribing Network and NPS MedicineWise. Sydney, NSW, Australia. Available from: https://cdpc.sydney.edu.au/wpcontent/uploads/2019/06/quality-use-of-medicines.pdf. Accessed March 1, 2021.

37. Steinman MA, Landefeld CS. Overcoming inertia to improve medication use and deprescribing. JAMA. 2018;320:1867-1869. doi:10.1001/jama.2018.16473

38. Medication without Harm. Global Patient Safety Challenge on Medication Safety. Geneva: World Health Organization; 2017. Available from:: https://www.who.int/patientsafety/medication-safety /medication-without-harm-brochure/en/. Accessed March 1, 2021.

39. Ailabouni NJ, Nishtala PS, Mangin D, Tordoff JM. Challenges and enablers of deprescribing: a general practitioner perspective. PLoS One. 2016;11:e151066. doi:10.1371/journal.pone.0151066
40. Smith H, Miller K, Barnett N, et al. Person-centred care including deprescribing for older people. Pharmacy (Basel, Switzerland). 2019. doi:10.3390/pharmacy 7030101

41. Jansen J, Naganathan V, Carter SM, et al. Too much medicine in older people? deprescribing through shared decision making. BMJ. 2016;353:i2893. doi:10.1136/bmj.i2893

42. Institute for Healthcare Improvement. What is an Age-Friendly Health System? Available from: http://www.ihi.org/Engage/ Initiatives/Age-Friendly-Health-Systems/Pages/default.aspx. Accessed June 06, 2021.

43. Ulley J, Harrop D, Ali A, Alton S, Fowler Davis S. Deprescribing interventions and their impact on medication adherence in community-dwelling older adults with polypharmacy: a systematic review. BMC Geriatr. 2019;19:15. doi:10.1186/s12877-019-1031-4

44. McKean M, Pillans P, Scott IA. A medication review and deprescribing method for hospitalised older patients receiving multiple medications. Intern Med J. 2016;46:35-42. doi:10.1111/imj.12906

45. O'Mahony D. Stopp/Start Criteria for potentially inappropriate medications/potential prescribing omissions in older people: origin and progress. Expert Rev Clin Pharmacol. 2020;13:15-22. doi:10.1080/ 17512433.2020.1697676

46. Ng B, Duong M, Lo S, Le Couteur D, Hilmer S. Deprescribing perceptions and practice: reported by multidisciplinary hospital clinicians after, and by medical students before and after, viewing an E-Learning Module. Res Social Adm Pharm. 2021. doi:10.1016/j. sapharm.2021.03.002

47. Kashyap M, Thuermann P, Le Couteur DG, Abernethy DR, Hilmer SN. Iuphar international geriatric clinical pharmacology curriculum for medical students. Pharmacol Res. 2019;141:611-615. doi:10.1016/j.phrs.2019.01.032

48. Gillaizeau F, Chan E, Trinquart L, et al. Computerized advice on drug dosage to improve prescribing practice. Cochrane Database Syst Rev. 2013;11:CD002894. doi:10.1002/14651858.CD002894.pub3

49. Rankin A, Cadogan CA, Patterson SM, et al. Interventions to improve the appropriate use of polypharmacy for older people. Cochrane Database Syst Rev. 2018;9:CD008165. doi:10.1002/ 14651858.CD008165.pub4

50. Roshanov PS, Fernandes N, Wilczynski JM, et al. Features of effective computerised clinical decision support systems: meta-regression of 162 randomised trials. BMJ. 2013;346:f657. doi:10.1136/bmj.f657

51. Monteiro L, Maricoto T, Solha I, Ribeiro-Vaz I, Martins C, MonteiroSoares M. Reducing potentially inappropriate prescriptions for older patients using computerized decision support tools: systematic review. J Med Internet Res. 2019;21:e15385. doi:10.2196/15385

52. Bloomfield HE, Greer N, Linsky AM, et al. Deprescribing for community-dwelling older adults: a systematic review and meta-analysis. J Gen Intern Med. 2020;35:3323-3332. doi:10.1007/ s11606-020-06089-2

53. Dalton K, O’Brien G, O'Mahony D, Byrne S. Computerised interventions designed to reduce potentially inappropriate prescribing in hospitalised older adults: a systematic review and meta-analysis. Age Ageing. 2018;47:670-678. doi:10.1093/ageing/afy086

54. Iankowitz N, Dowden M, Palomino S, Uzokwe H, Worral P. The effectiveness of computer system tools on potentially inappropriate medications ordered at discharge for adults older than 65 years of age: a systematic review. JBI Libr Syst Rev. 2012;10:798-831. doi:10.11124/jbisrir-2012-68

55. Fujita K, Kushida K, Okada H, Moles RJ, Chen TF. Developing and testing a set of quality indicators for pharmacist home visit services: a mixed methods study in Japan. Br J Clin Pharmacol. 2021;87:1940-1952. doi:10.1111/bcp.14587

56. Lawrence M, Olesen F. Indicators of quality in health care. Eur J Gen Pract. 1997;3:103-108. doi:10.3109/13814789709160336

57. Fujita K, Moles RJ, Chen TF. Quality indicators for responsible use of medicines: a systematic review. BMJ Open. 2018;8:e20437e020437. doi:10.1136/bmjopen-2017-020437 
58. Hermann RC, Mattke S, Somekh D, et al. Quality Indicators for International Benchmarking of Mental Health Care. Int J Qual Health Care. 2006;18(Suppl 1):31-38. doi:10.1093/intqhe/mzl025

59. Fastbom J, Johnell K. National indicators for quality of drug therapy in older persons: the Swedish Experience from the first 10 years. Drugs Aging. 2015;32:189-199. doi:10.1007/s40266-015-0242-4

60. Scottish Government Model of Care Polypharmacy Working Group. Polypharmacy Guidance (2nd Edition) 2015. Available from: https:// www.sehd.scot.nhs.uk/publications/dc20150415polypharmacy.pdf. Accessed March 31, 2021.

61. NSW Therapeutic Advisory Group. Inappropriate Polypharmacy Risk Assessment Tool (IPRAT) 2020. Available from: https://www. nswtag.org.au/wp-content/uploads/2020/11/Resource-Kit-forMeasuring-Strategies-to-Reduce-Harm-from-

Polypharmacy_Nov2020.pdf. Accessed March 31, 2021.

62. Mendelson A, Kondo K, Damberg C, et al. The effects of pay-forperformance programs on health, health care use, and processes of care: a systematic review. Ann Intern Med. 2017;166:341-353. doi:10.7326/M16-1881

63. van den Berg MJ, Kringos DS, Marks LK, Klazinga NS. The Dutch health care performance report: seven years of health care performance assessment in the Netherlands. Health Res Policy Syst. 2014;12:1. doi:10.1186/1478-4505-12-1

64. Teichert M, Schoenmakers T, Kylstra N, et al. Quality Indicators for Pharmaceutical Care: a Comprehensive Set with National Scores for Dutch Community Pharmacies. Int J Clin Pharm. 2016;38:870-879. doi:10.1007/s11096-016-0301-x

65. Warholak TL, West D, Holdford DA. The educating pharmacy students and pharmacists to improve quality program: tool for pharmacy practice. J Am Pharm Assoc (2003). 2010;50:534-538. doi:10.1331/ JAPhA.2010.10019

66. Heath I, Hippisley-Cox J, Smeeth L. Measuring performance and missing the point? BMJ. 2007;335:1075-1076. doi:10.1136/ bmj.39377.387373.AD

67. Pencheon D. The Good Indicators Guide: Understanding How to Use and Choose Indicators. NHS institute for Innovation and Improvement; 2008. Available from: https://fingertips.phe.org.uk/ documents/The\%20Good\%20Indicators\%20Guide.pdf. Accessed March 31, 2021.

68. Shea BJ, Hamel C, Wells GA, et al. Amstar is a reliable and valid measurement tool to assess the methodological quality of systematic reviews. J Clin Epidemiol. 2009;62:1013-1020. doi:10.1016/j. jclinepi.2008.10.009

69. Smith V, Devane D, Begley CM, Clarke M. Methodology in conducting a systematic review of systematic reviews of healthcare interventions. BMC Med Res Methodol. 2011;11:15. doi:10.1186/ 1471-2288-11-15

70. Viswanathan M, Patnode CD, Berkman ND, et al. Recommendations for assessing the risk of bias in systematic reviews of health-care interventions. J Clin Epidemiol. 2018;97:26-34. doi:10.1016/j. jclinepi.2017.12.004
71. Bühn S, Mathes T, Prengel P, et al. The risk of bias in systematic reviews tool showed fair reliability and good construct validity. J Clin Epidemiol. 2017;91:121-128. doi:10.1016/j.jclinepi.2017. 06.019

72. Pieper D, Buechter R, Jerinic P, Eikermann M. Overviews of reviews often have limited rigor: a systematic review. J Clin Epidemiol. 2012;65:1267-1273. doi:10.1016/j.jclinepi.2012.06.015

73. Pieper D, Antoine SL, Mathes T, Neugebauer EA, Eikermann M. Systematic review finds overlapping reviews were not mentioned in every other overview. J Clin Epidemiol. 2014;67:368-375. doi:10.1016/j.jclinepi.2013.11.007

74. Cardona M, Stehlik P, Fawzy P, et al. Effectiveness and sustainability of deprescribing for hospitalized older patients near end of life: a systematic review. Expert Opin Drug Saf. 2021;20:81-91. doi:10.1080/14740338.2021.1853704

75. Kua CH, Mak VSL, Huey lee SW. Health outcomes of deprescribing interventions among older residents in nursing homes: a systematic review and meta-analysis. $J$ Am Med Dir Assoc. 2019;20:362-372. e11. doi:10.1016/j.jamda.2018.10.026

76. Shrestha S, Poudel A, Steadman K, Nissen L. Outcomes of deprescribing interventions in older patients with life-limiting illness and limited life expectancy: a systematic review. Br J Clin Pharmacol. 2020;86:1931-1945. doi:10.1111/bcp.14113

77. Nakham A, Myint PK, Bond CM, Newlands R, Loke YK, Cruickshank M. Interventions to reduce anticholinergic burden in adults aged 65 and older: a systematic review. J Am Med Dir Assoc. 2020;21:172-180.e5. doi:10.1016/j.jamda.2019.06.001

78. Thillainadesan J, Gnjidic D, Green S, Hilmer SN. Impact of deprescribing interventions in older hospitalised patients on prescribing and clinical outcomes: a systematic review of randomised trials. Drugs Aging. 2018;35:303-319. doi:10.1007/s40266-018-0536-4

79. Wilsdon TD, Hendrix I, Thynne TR, Mangoni AA. Effectiveness of interventions to deprescribe inappropriate proton pump inhibitors in older adults. Drugs Aging. 2017;34:265-287. doi:10.1007/s40266017-0442-1

80. Reeve E, Ong M, Wu A, et al. Review of interventions to deprescribe benzodiazepines and other hypnotics among older people. Eur J Clin Pharmacol. 2017;73:927-935. doi:10.1007/s00228-017-2257-8

81. Johansson T, Abuzahra ME, Keller S, et al. Impact of strategies to reduce polypharmacy on clinically relevant endpoints: a systematic review and meta-analysis. Br J Clin Pharmacol. 2016;82:532-548. doi:10.1111/bcp.12959

82. Curtin D, Jennings E, Daunt R, et al. Deprescribing in older people approaching end of life: a randomized controlled trial using stoppfrail criteria. J Am Geriatr Soc. 2020;68:762-769. doi:10.1111/jgs.16278

83. New South Wales Therapeutic Advisory Group (NSW TAG) Polypharmacy Quality Use of Medicines (QUM) Indicators. Available from: https://www.nswtag.org.au/qum-indicators/. Accessed May 6, 2021.
International Journal of General Medicine

\section{Publish your work in this journal}

The International Journal of General Medicine is an international, peer-reviewed open-access journal that focuses on general and internal medicine, pathogenesis, epidemiology, diagnosis, monitoring and treatment protocols. The journal is characterized by the rapid reporting of reviews, original research and clinical studies
Dovepress

across all disease areas. The manuscript management system is completely online and includes a very quick and fair peer-review system, which is all easy to use. Visit http://www.dovepress.com/ testimonials.php to read real quotes from published authors. 